\title{
As particularidades e os fatores de sucesso na colaboração a distância entre professores no âmbito do projeto Cégep em Rede
}

\author{
Particularities and success factors of remote \\ collaboration between teachers within \\ the Cégep en Réseau project
}

Les particularités et facteurs de succès de la collaboration à distance entre enseignants dans le cadre du projet Cégep en Réseau

\section{Bruno Poellhuber ${ }^{[a]}$, Marie-Noëlle Fortin ${ }^{[b]}$ Sirléia Ferreira Silva Rosa ${ }^{[c]}$}

[a] Professor adjunto, membro do CRIFPE, Universidade de Montreal, Québec - Canadá, e-mail: bruno.poellhuber@umontrela.ca

${ }^{[b}$ Assistente de pesquisa, Universidade de Montreal, Québec - Canadá, e-mail: marienoelle59@yahoo.ca

[a] Doutoranda, membro do CRIFPE, Universidade de Montreal, Québec-Canadá, professora da Universidade Estadual de Minas Gerais (UEMG/FaE/CBH), Belo Horizonte, BH Brasil, e-mail: sirleia.ferreira.da.silva.rosa@umontreal.ca 


\section{Resumo}

Este artigo apresenta uma vertente dos resultados de um projeto de pesquisa-ação centrado na colaboração a distância (telecolaboração) entre professores de estabelecimentos distantes, a fim de favorecer o desenvolvimento profissional desses professores e dinamizar os programas oferecidos a pequenos grupos. De maneira muito específica, o artigo explica os fatores que contribuíram para o sucesso da colaboração a distância entre os professores participantes. Tal projeto, denominado Cégeps em Rede, conduzido pelo Cefrio (Centro Francófono de Informação das Organizações), consiste em agrupar classes de mesmos programas a pequenos grupos em Cégeps diferentes. Uma garantia do sucesso da colaboração entre professores - que a diferencia da colaboração a distância entre estudantes - parece ser uma comunicação frequente e contínua que se realiza por meio de uma diversidade de meios tecnológicos, bem como por encontros presenciais ocasionais. No âmbito da pesquisa, o desenvolvimento de um modelo teórico unificado aplicável tanto à colaboração entre professores quanto à colaboração entre estudantes, e tanto à colaboração a distância quanto à colaboração presencial, seria um avanço apreciável.

Palavras-chave: Colaboração a distância. Desenvolvimento profissional de professores. Trabalho em equipe.

\section{Abstract}

This article sets out part of the results obtained from an action research project focusing on remote collaboration (telecollaboration) between teachers from distant colleges, and aimed at fostering the professional development of teachers and stimulating education programs offered to small groups. More specifically, this article explains the factors that contributed to the success of the remote collaboration between participating teachers. The project, named Cégeps en Réseau ("Networked colleges") and managed by the Cefrio - Centre francophone d'information des organisations ("Frenchspeaking organizations' information center"), consisted in twining classes from different colleges sharing the same small group programs. The twining 
was made to allow collaboration between teachers and between students from these programs. One of the success factors of the teacher' collaboration-which differentiates it from the students' remote collaboration-seems to be frequent and continuous communication through a range of technological means, as well as occasional in person meetings. Regarding research, the development of a unified theoretical model applicable both to teachers' collaboration and students' collaboration, and both to remote collaboration and in person collaboration, would be a great advance.

Keywords: Remote collaboration. Teachers professional development. Team work.

\section{Résumé}

Cet article présente un volet des résultats d'un projet de recherche-action axé sur la collaboration à distance (télécollaboration) entre enseignants d'établissements distants, afin de favoriser le développement professionnel des enseignants et de dynamiser les programmes offerts à de petits groupes. De manière plus spécifique, l'article explique les facteurs qui ont contribué au succès de la collaboration à distance entre ces enseignants participant. Tel projet, appelé Cégeps en réseau, piloté par le Cefrio (Centre francophone d'information des organisations) consiste à jumeler des classes de mêmes programmes à petites cohortes données dans des cégeps différents. Ce jumelage est instauré afin de créer une collaboration entre les enseignants et entre les étudiants de ces programmes. Un des gages du succès de la collaboration entre enseignants qui la différencie de la collaboration à distance entre étudiants semble être une communication fréquente et continue qui se réalise par le biais d'une diversité de moyens technologiques ainsi que par des rencontres occasionnelles en présence. Sur le plan de la recherche, le développement d'un modèle théorique unifié applicable aussi bien à la collaboration entre enseignants qu'à la collaboration entre étudiants et à la collaboration à distance qu'à la collaboration en présence serait une avancée appréciable.

Mots-clef: Collaboration à distance. Développement professionnel des enseignants. Travail des équipes. 


\section{Contexto e problema}

Em Québec, no Canadá, os Cégeps são instituições de ensino pós-secundário que oferecem aos estudantes, com idade entre 16 e 18 anos, a escolha entre programas pré-universitários de duração de dois anos, que preparam para estudos universitários, ou programas técnicos, de duração de três anos, que preparam para o mercado de trabalho. A rede dos Cégeps permite tornar acessível a formação pós-secundária em todas as regiões do Québec.

Vários programas técnicos de nível colegial encontram dificuldades devido ao baixo número de inscrições, principalmente fora das grandes cidades. A redução demográfica que toca o conjunto da população quebequense é a principal causa desse fenômeno, que vai durar (INCHAUSPÉ, 2004). Outra causa é o êxodo dos jovens para os centros urbanos, já que $47 \%$ dos jovens de 20 a 34 anos deixam a sua região de origem, sendo que $70 \%$ desses não voltarão (GAUTHIER et al., 2001).

Esta baixa da clientela estudante causa fortes pressões financeiras e torna a manutenção desses programas difícil, apesar de eles responderem a necessidades regionais bem identificadas e contribuírem para o desenvolvimento socioeconômico regional. Esta situação cria também problemas relacionados à vitalidade do programa, que definimos como o desenvolvimento profissional dos professores e a diversidade dos recursos disponíveis para a aprendizagem (humanos, materiais, financeiros, tecnológicos). Nesses programas, os professores devem assumir numerosas preparações de cursos e ministrar aulas da disciplina principal do programa, apesar de não fazerem realmente parte da sua especialização. As ocasiões de trocas com os colegas tornam-se também mais limitadas e os professores correm o risco de sofrer isolamento. No programa, o problema é a diversidade de expertises dos professores. Os alunos têm frequentemente os mesmos professores em sessões diferentes. Esses têm poucos momentos de interação com pares diferentes, o que limita as suas possibilidades de desenvolver competências de trabalho em equipe. Por todas essas razões, finalmente, é a qualidade dos programas que pode ser colocada em risco. Esta situação de professores que trabalham com pequenos grupos e que dispõem de recursos limitados não é única no Québec nem específica ao ensino colegial. Ela se encontra em várias situações nas quais os estudantes são poucos e distribuídos num vasto território. 
Enquanto a formação a distância é o modo habitualmente utilizado para resolver os problemas de acessibilidade à formação no interior do Québec, é o aproveitamento da tecnologia para agrupar os professores e as classes que foi experimentado no projeto Cégeps em Rede entre 2006 e 2009. A colaboração a distância, apoiada pelas tecnologias, era aqui o principal meio utilizado para permitir aos professores dinamizar o seu ensino e compartilhar as suas expertises.

O presente artigo consiste em analisar as características das experiências de telecolaboração entre professores para identificar as melhores práticas. Trata-se aqui de focar nas experiências de colaboração dos professores por meio de recursos tecnológicos.

Tanto estudantes quanto professores identificaram as dificuldades da colaboração a distância entre estudantes como um dos principais aspectos negativos do projeto. Parece que a colaboração a distância comporta dificuldades e desafios específicos, sobretudo para os estudantes: o desconhecimento do outro, a fraca interdependência que se manifesta, por exemplo, na falta de responsabilização na realização das tarefas, nas dificuldades de coordenação do trabalho em equipe, na falta de meios para solucionar os problemas que ocorrem nas equipes, na defasagem entre os conteúdos abordados pelos professores agrupados ou na avaliação da aprendizagem (POELLHUBER et al., 2010). As dificuldades técnicas encontradas durante a experiência exacerbaram alguns desses problemas, especialmente a coordenação do trabalho em equipe.

Porém, do ponto de vista dos professores, a colaboração com os colegas distantes e os frutos dessa colaboração (troca de conhecimentos disciplinares e de material pedagógico) surge claramente como a repercussão mais positiva do projeto (POELLHUBER et al., 2010). Essa colaboração desenvolveu-se, sobretudo a distância, por meio dos instrumentos tecnológicos, mas também se realizou algumas vezes presencialmente. Então, procuramos compreender quais são essas particularidades e exigências da colaboração a distância na perspectiva das diferenças de resultados para estudantes e professores.

Depois de uma breve síntese de diferentes modelos que nos permitem abordar a colaboração entre professores, apresentaremos resumidamente o modelo de desenvolvimento profissional sobre o qual nos baseamos para em seguida descrever a maneira como os professores colaboravam no projeto, para tentar identificar as características ligadas 
ao sucesso dessa colaboração. Em seguida, apresentaremos o percurso metodológico, para, enfim, ressaltar os principais temas emergentes das entrevistas sobre a colaboração dos professores.

\section{Referencial teórico}

\section{A colaboração entre os professores}

De maneira geral, em sua base, a colaboração é uma atividade realizada entre participantes que têm objetivos comuns e que investem esforços coordenados para o alcance de resultados cujo sucesso é compartilhado entre os membros do grupo (AUSTIN; BALDWIN, 1991 apud KOCHAN; MULLEN, 2003). A principal vantagem é que as novas soluções que emergem disso não poderiam aparecer se as pessoas trabalhassem isoladamente (FORMAN; CAZDEN, 1985). A colaboração distingue-se da competição na sua abordagem e nos seus valores. Trata-se de um fenômeno social no qual entram em relação dois ou mais indivíduos.

As abordagens teóricas que permitem tratar do fenômeno da colaboração são particularmente bem desenvolvidas para os estudantes, mas menos para os professores. Contudo, é possível identificar os elementos comuns às teorias da aprendizagem cooperativa, da aprendizagem colaborativa e às teorias dos pequenos grupos.

Por um lado, a aprendiagem cooperativa implica em uma estrutura específica na qual certas etapas levam um grupo para o alcance de um objetivo comum, num espírito de responsabilidades mútuas (KAGAN, 1985). As responsabilidades e as diversas tarefas são divididas entre os participantes, mas, ao agir, cada membro permite o alcance do objetivo pelo conjunto do grupo. A interação que se opera entre os indivíduos pode tomar diversas formas, incluindo a ajuda, a troca de informações, a retroação pelos pares, a controvérsia, o compromisso público, a motivação e a confiança interpessoal (JOHNSON; JOHNSON, 1994).

Os pilares da aprendizagem cooperativa são: a busca de um objetivo comum, o estabelecimento de um clima de colaboração, a interdependência positiva dos membros na busca desse objetivo (frequentemente estruturado por uma combinação de recompensas de grupo ligadas aos desempenhos individuais), uma estruturação forte das atividades, o retorno sobre o funcionamento do grupo. 
Embora a aprendizagem colaborativa compartilhe várias características com a aprendizagem cooperativa, aquela se distingue sob vários aspetos. A aprendizagem colaborativa é menos estruturada do que a aprendizagem cooperativa e a interdependência dos membros é menos forte (KELLER, 2004). Atribui, no entanto, um lugar essencial ao grupo e aos seus aspectos benéficos.

Segundo Yves St-Arnaud (1978), que propõe a teoria do funcionamento dos grupos restritos, um grupo ótimo é "um campo psicológico produzido pela interação de três pessoas ou mais, reunidas em situação de face a face na pesquisa, na definição, na busca de um alvo comum; na interação de cada uma dessas pessoas com esse alvo comum e na interação das pessoas entre elas" (ST-ARNAUD, 1978, p. 26). Essa definição ressalta a importância do alvo comum (ou de um objetivo comum), a importância da interação com o alvo (ou das ações empreendidas para atingir o objetivo, designado por processo de produção), bem como a importância dos fatores socioafetivos ligados às interações entre as pessoas (definidos por St-Arnaud como o processo de solidariedade), tal como o desenvolvimento da confiança interpessoal. St-Arnaud destaca também a importância dos processos de coordenação e de retorno sobre o funcionamento do grupo na busca de uma dinâmica de grupo ótima. Outras teorias dos pequenos grupos tratam de maneira semelhante esses diferentes componentes.

Algumas pesquisas parecem demonstrarque muitos dos fenômenos de grupo presentes nos grupos que se encontram face a face reproduzem-se nos ambientes em que a comunicação é midiatizada pela tecnologia. Assim, o modelo de Salmon (2000) ressalta a importância do desenvolvimento de um clima socioafetivo favorável na primeira fase do desenvolvimento dos grupos virtuais e a importância das funções de coordenação e de regulação das trocas nos fóruns de discussão dos cursos a distância.

As teorias dos pequenos grupos e as teorias sobre a aprendizagem cooperativa e a aprendizagem colaborativa têm em comum certos elementos fundamentais: a presença de um objetivo comum, ao redor do qual os participantes estabelecem uma interdependência positiva, a importância do estabelecimento de um clima socioafetivo favorável e do processo socioafetivo em geral, uma divisão de tarefas e de responsabilidades na busca do objetivo, os processos de regulação do funcionamento do grupo (coordenação, resolução dos problemas de grupo, etc.) 
No âmbito do projeto Cégeps em Rede, pelo fato de a colaboração ter sido estabelecida entre professores, essa tomou essencialmente a forma do coensino, que consiste numa divisão de responsabilidades entre professores de diferentes especialidades, que trazem à classe uma expertise específica (SHAPLIN; OLDS, 1964). O coensino permitiria diminuir o sentimento de isolamento dos professores e enriquecer a formação oferecida aos alunos e o trabalho dos professores (MURATA, 2002). No caso da presente pesquisa, pode-se falar de coensino em rede.

\section{Desenvolvimento profissional}

Abordagens recentes sobre o desenvolvimento profissional consideram os professores como aprendizes, inspirando-se nas teorias da aprendizagem de caráter mais cognitivista e socioconstrutivista (KNIGHT, 2002). Clarke e Hollingsworth (2002) apresentam um modelo interligado e sistêmico de crescimento profissional muito menos linear do que os modelos anteriores. Esse modelo foca nos processos de reflexão e de ação na mudança. De acordo com Clarke e Hollingsworth (2002), o desenvolvimento profissional é essencialmente o resultado de um processo reflexivo que provoca mudanças de prática permanentes. Nesse tipo de concepção, toda experiência de aprendizagem natural ou informal (como os encontros e as discussões) faz parte do desenvolvimento profissional (UWAMARIYA; MUKAMURERA, 2005). Levando em conta a importância dos aspectos informais do desenvolvimento profissional no presente projeto, é esse o modelo que escolhemos. $\mathrm{O}$ espaço restrito não nos permite, contudo, expô-lo de maneira detalhada.

\section{Metodologia}

O projeto Cégeps em Rede, pilotado pelo Cefrio (Centre Francophone d'Information des Organisations/Centro Francófono de Informação das Organizações) desenvolveu-se em sete projetos que agrupam onze Cégeps. O projeto consiste em agrupar classes de mesmos programas a pequenos grupos em Cégeps diferentes. Esse agrupamento é instaurado a fim de criar uma colaboração entre os professores e entre os estudantes desses programas. Pesquisa-ação 
Esse projeto de pesquisa baseia-se numa metodologia de pesquisaação que privilegia a colaboração entre pesquisadores e atores do campo, recorrendo a diferentes momentos de transferências da pesquisa para o campo e vice-versa. Essa metodologia caracteriza-se por um duplo objetivo, o da pesquisa visando produzir conhecimentos e o objetivo de ação, que se ilustra na resolução de problemas de campo.

\section{Participantes}

Os projetos foram selecionados pela equipe do Cefrio após chamadas de projetos lançadas no outono de 2005 e no outono de 2007. Cinco projetos aconteceram durante a primeira fase, dois dentre eles prolongados para a segunda fase. Dois novos projetos foram acrescentados no outono de 2007. O número de participantes do projeto era variável de uma sessão a outra. Para os quatro projetos da segunda fase, os participantes consistiam em vinte professores, oito pessoas para o suporte TIC, uma dúzia de coordenadores e cerca de 80 estudantes.

\section{Recursos tecnológicos utilizados}

Para o conjunto do projeto, três instrumentos básicos foram sugeridos e utilizados: a janela de telepresença (um sistema de videoconferência), Via (um sistema de visioconferência web sincrônico semelhante ao Adobe ${ }^{\circledR}$ Connect e ao Elluminate) e DECclic (um ambiente digital de aprendizagem assíncrona com recursos compartilhados e fórum de discussão). Os professores tinham a liberdade de utilizar outros instrumentos tecnológicos e vários foram utilizados (Skype, softwares para criação de questionários de múltipla escolha, wikis, etc.).

\section{Instrumentos de coleta de dados}

No que diz respeito ao objetivo visado pela presente comunicação, a coleta de dados consistiu essencialmente na realização de seis entrevistas de grupo com os professores do projeto, durante a sessão de inverno de 2008. Entrevistas individuais também foram realizadas, bem como gruposfocais destinados a fazer o balanço das melhores atividades. 


\section{Análise das entrevistas dos professores}

As seis entrevistas de grupos do inverno de 2008, realizadas com os estudantes e professores, foram gravadas e transcritas. Como sugerido por Miles e Huberman (2003), uma primeira codificação foi realizada com uma grade de codificação descritiva comportando categorias bastante amplas. Um segundo membro da equipe de pesquisa retomou as análises tematizando cada uma das entrevistas de maneira mais precisa. O resultado ressalta os principais temas tratados pelos professores.

\section{Resultados}

Os temas que surgiram das entrevistas com os professores dizem respeito à composição das equipes, aos objetivos compartilhados entre os membros das equipes e à interdependência positiva que se desenvolveu entre eles. O processo de colaboração e a divisão das tarefas também foram descritos de maneira detalhada pelos professores.

\section{Composição das equipes, interdependência e objetivos}

\section{Composição das equipes}

Geralmente, no início de cada projeto, os membros de cada departamento reúnem-se presencialmente para discutir o projeto, o seu programa e as suas orientações. Os agrupamentos potenciais de professores foram identificados em seguida com base em uma comparação entre as grades de cursos dos dois departamentos. O interesse individual pelo projeto influenciava também os agrupamentos. Em geral os professores agrupados não se conhecem antes de começar a sua colaboração, mas o encontro presencial permite-lhes detectar afinidades e interesses em comum com eventuais parceiros. Esse processo de agrupamento se desenvolve bem na maior parte do tempo, embora certos agrupamentos sejam menos harmoniosos.

\section{Conhecimento dos colegas}

Os professores gostam de colaborar e encontram nisso um enriquecimento em vários níveis. Para assegurar o bom funcionamento 
da colaboração, eles apontam a importância de se conhecerem bem e de trabalharem tanto quanto possível com as mesmas pessoas. $\mathrm{Na}$ grande maioria dos casos, as relações são excelentes, um bom clima se estabelece, trocas construtivas e uma comunicação eficaz nutrem os dois colegas. A comunicação entre os professores agrupados é periódica e aposta em encontros presenciais ocasionais ou mesmo em contatos midiatizados pelas tecnologias (trocas no Skype ou por correio eletrônico, reuniões pelo sistema de visioconferência ou de videoconferência). Os professores demonstram apreciar o enriquecimento disciplinar, pedagógico e tecnológico, mas apreciam também as qualidades pessoais de seu correspondente. Para alguns, a relação evolui para uma amizade.

Sim, sobre o plano das afinidades, colaboramos bem juntos. Falamos de um monte de outras coisas. Tornamos como colegas de trabalho, ainda que a distância. É essa a parte interessante (PROFESSOR H08).

\section{Interdependência}

Os professores são intrinsecamente interdependentes para o sucesso das atividades de agrupamento das classes. Para cada um, a qualidade da intervenção do outro tem um impacto direto sobre o sucesso das atividades e do curso, o que implica um grau elevado de confiança profissional. Uma boa utilização da complementaridade das expertises da disciplina e da pedagogia favorece essa interdependência positiva. Essa divisão de expertises é apreciada e ajuda cada professor no alcance dos seus objetivos pessoais.

Como ele ensina e como apresentou o seu conteúdo. É bacana discutir sobre este assunto. Se ganha também expertise no sentido que quando o professor apresenta algo... que é o seu assunto específico que eu conbeço menos (com o qual eu lidava menos ou mesmo nem um pouco) lá eu aprendo ao mesmo tempo em que os alunos. Isso é interessante. Tenho o conteúdo e eu sigo o curso ao mesmo tempo. O professor me envia as suas notas de cursos e os seus materiais e eu sou capaz de dar sequência (PROFESSOR H08).

A complementaridade das expertises pode manifestar-se de diversas maneiras. Em certos casos, um professor com experiência se vê agrupado com um professor novo. Esse se beneficia dos conselhos, da experiência 
e da expertise pedagógica do mais experiente. Este, em comparação ao outro, encontra as vantagens da energia, das ideias e do olhar novo do menos experiente.

\section{Compatibilidade da visão do projeto e das abordagens pedagógicas}

Nos poucos casos de agrupamento com menos êxito, uma demasiada diferença de abordagens pedagógicas ou de visão do projeto parecem justamente prejudicar a interdependência positiva. Essas diferenças parecem prejudicar a continuação dos objetivos comuns ou compatíveis. De fato, quando essas não são demasiadamente importantes, os professores apreciam as diferenças nas abordagens pedagógicas e as consideram como enriquecedoras. Certas equipes afirmam utilizar sensivelmente a mesma abordagem, mas outras explicam que os seus métodos pedagógicos são diferentes, porém compatíveis. $\mathrm{O}$ fato de terem abordagens pedagógicas compatíveis parece um elemento que contribui para o sucesso da colaboração entre os professores.

Um dia, por exemplo, era o Lévi quem me supervisionava a atividade e na semana seguinte, é o contrário. Mesmo assim tínhamos um interesse. Eu te diria que a outra vantagem, é que você fica 45 horas com os mesmos estudantes sem ter a mesma abordagem. Mas eles chegam com um outro tipo de trabalho, com um ponto vista do outro professor [...] Compativeis... eu diria que sim. É certo que cada um tem sua abordagem, mas quando chega a atividade, não bá dificuldade em entender-se (PROFESSOR).

\section{Organização do trabalho em equipe}

\section{Divisão das tarefas}

Em geral, as atividades de telecolaboração são organizadas por equipes restritas de professores. As equipes são compostas de dois ou três professores agrupados. Nessas duplas ou trios, um planejamento global é feito em equipe para determinar as linhas gerais da atividade. Em seguida, diferentes formas de divisão das tarefas se instalam nas equipes para o conjunto das atividades e para as diferentes atividades (planejamento e preparação, execução, avaliação). Por último, as tarefas são distribuídas concretamente a cada um dos professores. 
É importante, também, quando você é muito ocupado: um toma conta de uma coisa e o outro toma conta de outra coisa. É interessante. Sim, você trabalha em equipe, você pode conversar sobre suas ideias, sobre o que vamos fazer. Depois disso, o trabalbo é feito quando a gente se separa. Somos produtivos ao mesmo tempo (PROFESSOR).

Na maior parte das equipes, as decisões são tomadas conjuntamente, quer seja sobre os critérios de correção, as divisões das tarefas ou o desenvolvimento específico da atividade. Em certos casos, um dos professores tem a responsabilidade da vertente mais técnica, enquanto o outro executa as tarefas conexas. Em vários casos, os professores decidem ensinar conjuntamente uma parte do conteúdo. Essa fórmula de dividir o trabalho coletivo exige muito tempo de coordenação e encontros extraclasse, porém com repercussões notáveis sobre a qualidade das atividades. Em outros casos, os professores optam por uma fórmula mais simples de divisão das tarefas. Eles convêm desde o início que cada um dos professores terá a liderança de uma atividade de colaboração a distância, enquanto o outro oferece apoio. Esse tipo de divisão é mais eficaz em termos de logística, mas parece ser menos eficaz para a adaptação de conhecimentos disciplinares e pedagógicos conduzidos pelo outro professor.

\section{Logística da preparação das atividades nos cursos agrupados}

Na maioria das vezes, os professores se encontram antes de começar a sessão, determinam os objetivos a serem atingidos e as etapas do caminho. Procedem igualmente à troca dos planos de cursos, das suas notas, ajustam os seus conteúdos e planejam as atividades de telecolaboração. Em seguida, os encontros acontecem a distância, antes do curso, no qual há uma atividade de telecolaboração, frequentemente uma vez por semana. Os professores comparam seus conteúdos e planejam o desenvolvimento da lição.

Geralmente a preparação se desenvolve bem e os professores devem assegurar que as atividades sejam apresentadas em momentos que convêm aos dois horários. No fim de cada sessão, um balanço é feito presencialmente pelos professores e permite aperfeiçoar as atividades. Certas equipes de professores efetuam um balanço após cada uma das atividades em que as classes são agrupadas. As equipes de professores mais funcionais fazem retornos sistemáticos sobre as atividades e pedem na ocasião a opinião dos estudantes sobre as atividades, visando a melhorá-las. 
Ao longo das sessões, a preparação e a colaboração melhoram, os professores se conhecem melhor e a cumplicidade cresce. O estabelecimento da interdependência positiva parece ligado à confiança que se desenvolve entre os professores. A experiência adquirida permite reutilizar atividades que tiveram sucesso e que foram melhoradas, reduzindo, assim, o tempo de preparação. Alguns professores pedem aos seus estudantes que façam em classe as atividades elaboradas para a telecolaboração. Em suma, a preparação das atividades efetua-se ao mesmo tempo de forma rigorosa e convivial.

No início da sessão, focamos nos cursos em que haveria as atividades. Fizemos células. Exemplo: dois professores que tinham que montar uma atividade. Planejávamos a atividade a dois. Montávamos. Nós nos atribuíamos os papéis e, uma vez que estava montada, cada um de nós tinha o próprio papel. Nesse caso, também, poderia ser um Cégep a supervisionar a atividade. Em seguida era o outro. Às vezes, eram os dois. As atividades, tal qual, tínhamos planejado juntos ((PROFESSOR H08).

\section{Adaptação de atividades testadas}

Em várias equipes, os professores reutilizam material do seu curso em classe e o adapta ao contexto da telecolaboração. A divisão das tarefas leva em conta quem é a pessoa que desenvolveu a atividade. A vantagem desta fórmula é partir de uma atividade já testada em classe. Essa fórmula requer menos investimento de tempo e constitui uma fórmula de divisão do material pedagógico, sendo ao mesmo tempo uma fonte de enriquecimento disciplinar e pedagógico para os professores.

Eles tinham uma seção do curso onde faziam vir alguém que os mostrava os sistemas pneumáticos. [...] Então ele tinha um especialista, um vendedor de equipamentos que trabalhava na induistria que ele conhecia; então, ele vinha todos os anos faz̧er uma pequena demonstração. Então ele disse: "Vamos tentar fazêe-lo no VIA nesse momento (PROFESSOR H09).

Às vezes as tarefas entre os professores podem ser desequilibradas devido às diferenças no acesso a equipamentos especializados ou nas expertises. A divisão do trabalho permanece, no entanto, possível:

Eu olhava às vežes o seu material [do outro professor], e me dizia: "Ah, sim, poderia adaptá-lo desta maneira...". Eu saía com os seus materiais, 
porque a sua contribuição tinha sido me passar o formato tradicional, então, eu tentava adaptá-lo (PROFESSOR H09).

A divisão das tarefas se faz à luz do trabalho já realizado, utilizando às vezes atividades já testadas e aprovadas nas classes dos professores. As equipes de professores que funcionam melhor combinam uma divisão equitativa das tarefas e uma participação comum no planejamento e na realização das atividades.

\section{Logística de desenvolvimento das atividades}

Obom desenvolvimento das atividades necessita deum planejamento rigoroso por parte dos professores. Devem, entre outras coisas, supervisionar o bom funcionamento do material informático antes do início da lição. A organização é conveniente, visto que o bom desenvolvimento de uma atividade de telecolaboração permanece imprevisível devido ao número de pessoas implicadas, à dinâmica dos dois grupos e aos riscos de problemas técnicos.

Para os professores, as atividades de telecolaboração dos estudantes requerem um acompanhamento mais próximo. Devem, sobretudo, consagrar tempo à gestão de conflitos nos trabalhos de equipe dos estudantes. Os professores ficam atentos quanto à composição das equipes de estudantes e cuidam de mudá-las se necessário.

\section{Coordenação do trabalho em equipe}

A coordenação do trabalho em equipe entre os professores estabelece-se por uma comunicação regular e contínua, podendo ser presencialmente ou a distância. Nos casos de uma comunicação a distância, os professores utilizam diferentes recursos tecnológicos, como o correio eletrônico, Skype, Via, "janela de telepresença”. A mistura da presença e da distância parece favorecer o desenvolvimento de um clima de colaboração, assim como a utilização de meios de comunicação sincrônicos (Skype, Via, "janela de telepresença”). A totalidade das equipes reúne-se pelo menos duas vezes por sessão, mas há algumas mais frequentes. Outro elemento que favorece a coordenação das equipes é o fato de os professores agrupados ganharem um horário reservado à colaboração com seu correspondente. 


\section{Problemas nas equipes}

$\mathrm{Na}$ colaboração entre os professores, os problemas de equipe permanecem mínimos. As diferenças nas abordagens pedagógicas constituem a principal fonte de agrupamentos sem êxito. As mudanças de pessoal (saída de um professor) vêm às vezes perturbar uma colaboração bem estabelecida e sobrecarregam a tarefa, pois é necessário retomar uma parte do processo com o novo professor agrupado. A integração de novos professores nas equipes constitui um desafio específico.

No que diz respeito à defasagem dos conteúdos, contrariamente aos estudantes que, às vezes, consideram que as diferenças nos conteúdos e nas abordagens são prejudiciais (frequentemente devido às diferenças que induzem nas avaliações somativas), os professores consideram essas diferenças, por outro lado, enriquecedoras, apesar dos desafios que representam.

\section{Discussão dos resultados}

Vários fatores distinguem a telecolaboração entre professores e a telecolaboração entre estudantes. Em primeiro lugar, as equipes de professores são mais restritas e colaboram em períodos mais longos e com projetos de maior amplitude. Para os professores, os benefícios da colaboração a distância são mais aparentes. Percebem rapidamente o enriquecimento potencial que provém da colaboração com professores que têm uma expertise disciplinar e pedagógica diferente.

Além disso, a colaboração com colegas distantes parece poder tirar os professores da dinâmica da equipe local e restrita à qual pertencem. A colaboração com os colegas do seu departamento não é necessariamente mais fácil do que a colaboração com os seus colegas distantes. Em certos casos, é possível que tenham mais afinidades pedagógicas com os últimos.

Se os professores compartilharem uma visão comum do projeto e tiverem abordagens pedagógicas suficientemente semelhantes para serem compatíveis, mas suficientemente diferentes para serem enriquecedoras, parece possível estabelecer uma colaboração frutífera. $O$ fato de terem abordagens pedagógicas compatíveis e de compartilharem uma visão semelhante do projeto parece favorecer o estabelecimento de objetivos comuns ou compatíveis, um componente essencial da eficácia do trabalho em equipe. 
A própria estrutura das atividades de telecolaboração torna os professores interdependentes uns dos outros para o sucesso de suas atividades e de seus cursos. A contribuição de outra expertise disciplinar ou pedagógica representa uma vantagem importante nessa perspectiva. De acordo com as teorias dos pequenos grupos, essa interdependência positiva teria um papel crucial no sucesso do trabalho das equipes.

Uma garantia do sucesso da colaboração entre professores - que a diferencia da colaboração a distância entre estudantes - parece ser uma comunicação frequente e contínua que se realiza por meio de uma diversidade de meios tecnológicos, bem como por encontros presenciais ocasionais. Essa comunicação constante facilita vários processos de grupo, por permitir aos professores se conhecerem mais, nos planos pessoal e pedagógico, apesar da distância, facilitando a coordenação do trabalho das equipes e limitando os impactos negativos dos problemas técnicos que afetam uma ou outra das tecnologias utilizadas. A coordenação do trabalho das equipes também é facilitada pelo fato de os professores agrupados chegarem a reservar horários para a colaboração no seu horário de curso. Em várias equipes, boas relações desenvolvem-se e os parceiros tornam-se praticamente colegas, ou mesmo amigos. Isso exige certas atitudes favoráveis à colaboração: respeito, escuta. Uma divisão equitativa das tarefas facilita também o bom desenvolvimento do trabalho das equipes de professores.

Em suma, a colaboração a distância entre professores parece poder realizar-se mais facilmente e trazer mais rapidamente benefícios aos professores que a praticam do que a colaboração a distância entre estudantes. Contudo, alguns agrupamentos têm, às vezes, insucessos e, em certos casos, os efeitos sobre o desenvolvimento profissional dos professores podem ser ausentes, ou até mesmo negativos, e o interesse pela telecolaboração pode diminuir consideravelmente.

\section{Conclusão}

Os elementos identificados como essenciais ao sucesso da colaboração pelas teorias dos pequenos grupos e pelas teorias da aprendizagem cooperativa ou colaborativa reencontram-se no discurso dos professores: objetivos comuns (visão semelhante dos objetivos do projeto e compatibilidade das abordagens pedagógicas), interdependência positiva, fatores socioafetivos (conhecimento dos colegas), compartilhamento 
das tarefas e das responsabilidades. As condições nas quais se efetua a colaboração a distância entre professores parecem mais favoráveis ao sucesso dessa colaboração do que as condições da colaboração entre estudantes. A colaboração efetua-se com uma duração mais longa. A regularidade das comunicações e a diversidade dos meios utilizados parecem anular os efeitos negativos dos problemas técnicos. Numa outra vertente da pesquisa, pôde-se ver que os efeitos da colaboração a distância entre professores são positivos para o seu desenvolvimento profissional (POELLHUBER et al., 2010).

No conjunto, parece que a telecolaboração entre professores constitui uma via promissora para as situações nas quais as equipes de professores tornam-se restritas, em que os professores são isolados, por exemplo, nos casos nos quais a formação é oferecida a uma clientela dispersa num território vasto. $\mathrm{O}$ tempo requerido para o desenvolvimento de atividades conjuntas pode ser importante, mas certas fórmulas permitem diminuí-lo, como a adaptação de atividades já testadas em contexto de classe ou a reutilização de atividades de telecolaboração entre estudantes.

Esta pesquisa comporta, contudo, certos limites. É fundada unicamente em depoimentos e baseia-se num número restrito de entrevistas. Foi realizada num contexto muito específico no qual os professores eram fortemente incitados a colaborar, participando de um projeto com o qual seu estabelecimento de ensino havia se comprometido. Alguns poderiam fazer objeção à utilização de categorias procedentes de teorias essencialmente fundadas sobre a colaboração presencial para um contexto de colaboração em parte a distância. Além disso, o fato de colocar em evidência essas categorias representa também o interesse principal da presente pesquisa.

Os dados obtidos sobre a colaboração entre professores conduzemnos a sugerir que os elementos seguintes facilitam a colaboração a distância entre professores: grades de cursos semelhantes; momentos de troca sobre as abordagens pedagógicas e a visão do projeto; uso de práticas de comunicação regular que apostem, ao mesmo tempo, em encontros presenciais ocasionais e numa diversidade de instrumentos tecnológicos síncronos e assíncronos; recurso à adaptação ao contexto da telecolaboração em classe e a proposta de meios que permitam facilitar a reutilização das atividades de telecolaboração já realizadas (por exemplo, por um sistema de compartilhamento do material pedagógico e de cenários de atividades).

No âmbito da pesquisa, o desenvolvimento de um modelo teórico unificado aplicável tanto à colaboração entre professores quanto 
à colaboração entre estudantes, e tanto à colaboração a distância quanto à colaboração presencial, seria um avanço apreciável. As pesquisas sobre a colaboração a distância entre professores em contextos mais diversificados com uma instrumentação que recorresse também a medidas mais diretas da colaboração (como a observação ou a gravação das sessões de colaboração) reforçariam também as conclusões.

\section{Referências}

CLARKE, D.; HOLLINGSWORTH, H. Elaborating a model of teacher professional growth. Teaching and Teacher Education, v. 18, p. 947-967, 2002.

FORMAN, E.; CAZDEN, C. Exploring Vygotskian perspectives in education: the cognitive value of peer interaction, In: WERTSCH, J. (Ed.), Culture, cognition and communication: Vygotskian perspectives. New York: Cambridge University Press, 1985.

GAUTHIER, M. et al. La migration des jeunes au Québec. Résultats d'un sondage auprès des 20-34 ans du Québec. Montréal, Québec: INRS, Urbanisation, Culture et Société, 2001.

INCHAUSPÉ, P. Projet les cégeps en réseau: la mise en réseau de programmes techniques en difficulté peut-elle permettre leur consolidation? Montréal, Québec: CEFRIO, 2004.

JOHNSON, D. W.; JOHNSON, R. T. Learning together and alone: cooperative, competitive, and individualistic learning. 4th. ed. Boston: Allyn \& Bacon, 1994.

KAGAN, S. Dimensions of cooperative classroom structures: learning to cooperate, cooperating to learn. New York: Plenum Press, 1985.

KELLER, J. The effects of high-structure cooperative versus low-structure collaborative design of decision change, critical thinking, and interaction pattern during online debates. Association for Educational Communications and Technology, v. 27, p. 19-23, 2004.

KOCHAN, F. K.; MULLEN, C. A. An exploratory study of collaboration in higher education from women's perspectives. Teaching Education, v. 14, n. 2, p. $153-167,2003$. 
KNIGHT, P. A systemic approach to professional development: learning as practice. Teaching and Teacher Education, v. 18, p. 229-241, 2002.

MURATA, R. What does team teaching mean? A case study of interdisciplinary teaming. The Journal of Educational Research, v. 96, n. 2, p. 67-77, 2002.

POELlHUBER, B. et al. Projet Cégeps en réseau: rapport final - volet technopédagogique de la recherche. Québec: CEFRIO, 2010.

SALMON, G. E-moderating: the key to teaching and learning online. London: Kogan Page, 2000.

SHAPLIN, J. T.; OLDS, H. F. Team teaching. New York: Harper \& Row, 1964.

ST-ARNAUD, Y. Les petits groupes: participation et communication. Montréal: Les Presses de l’Université de Montreal; Les Éditions du CIM, 1978.

UWAMARIYA, A.; MUKAMURERA, J. Le concept de "développement professionnel” en enseignement: approches théoriques. Revue des Sciences de L'Éducation, v. 31, n. 1, p. 133-155, 2005.

Recebido: 15/04/2010

Received: 04/15/2010

Aprovado: 22/06/2010 Approved: 06/22/2010 